\title{
O Estudo de Tradução Técnica e Científica: Uma Análise de seu Desenvolvimento Histórico'
}

\author{
Javier Franco Aixelá* \\ Traduzido por Pedro Luís Sala Vieira**
}

\section{Introdução}

A tradução técnica e científica se constitui tradicionalmente como bedel das discussões teóricas sobre tradução. A lógica por trás da abordagem deste ramo da tradução consiste na ideia de que a literatura envolve uma prática linguística de caráter criativo que exige do tradutor uma reescrita em outra língua que acompanhe tal caráter criativo, enquanto tradutores de textos técnicos e científicos trabalham apenas com um tipo de discurso no qual o vocabulário (a terminologia) é ou tende a ser unívoco, com os termos correspondentes disponíveis de antemão e a linguagem (estilo) utilizada seria simples e direta. Em outras palavras, bastaria um domínio razoável da língua e um alto nível de conhecimento técnico ou científico para escrever um bom texto técnico (ou científico), enquanto poucos seriam capazes de escrever um bom poema ou romance, mesmo na própria língua materna - o mesmo se aplicando à tradução. Portanto, a tradução literária (incluindo a Bíblia) sempre requereu maior reflexão, enquanto a tradução técnica apenas necessitava de profissionais competentes com bom conhecimento terminológico de suas respectivas áreas.

\footnotetext{
${ }^{1}$ Este artigo foi publicado originalmente em inglês na revista JosTrans - Journal of Specialised Translation. Agradecemos ao autor e editores pela autorização concedida em publicar esta tradução. Referência completa do artigo: FRANCO AIXELÁ, Javier "The Study of Technical and Scientific Translation: An Examination of its Historical Development" Journal of Specialised Translation, v.1, p. 29-49, 2004.

* Javier Franco Aixelá é docente na área de tradução do par Espanhol-Inglês da Universidade de Alicante (Espanha), onde leciona tradução literária e médica e teoria da tradução.

** Pedro Sala Vieira é graduado em Letras Português-Inglês pela Faculdade de Letras da UFRJ e mestrando em Linguística Aplicada na mesma faculdade.
} 
FRANCO AIXELÁ, O Estudo de Tradução Técnica e Científica

Traduzido por VIEIRA

Autores clássicos da teoria da tradução, como o sempre referido Schleiermacher, não costumam atribuir o título de tradutor àqueles que trabalham com textos não-literários ou puramente acadêmicos (sobretudo filosóficos e religiosos), o que representa perfeitamente a linha de raciocínio tradicional acerca desta questão. Permitam-me citar um trecho pouco conhecido de um famoso texto desse autor traduzido para o inglês:

\begin{abstract}
Quanto menos o próprio autor aparece no original, mais ele age como um mero instrumento de um objeto, e quanto mais ele adere à ordem "espaço e tempo", mais a tradução depende de uma simples interpretação. Deste modo, o tradutor de um artigo de jornal e de uma simples literatura de viagem se assemelha, em primeira análise, a um intérprete, e acaba correndo o risco de ser ridicularizado, caso clame pelo reconhecimento de seu trabalho como se fosse um artista. Por outro lado, quanto mais particularidades do autor estiverem representadas no texto, como a sua visão de mundo e seu estilo de escrita, quanto mais liberdade ele tiver na escolha de uma determinada ordem, ou uma ordem definida por avaliação própria, mais prestígio terá o seu trabalho do ponto de vista artístico [...] Nesta escala bidimensional, portanto, o tradutor se posiciona cada vez mais acima do intérprete até alcançar a área que lhe convier melhor, isto é, os produtos da mente acadêmica e artística nos quais a capacidade de combinar idiossincrasias do autor e o espírito da língua que serve como o receptor de um sistema de observações e variações de humor compõem o todo, no qual o objeto não domina em nenhum âmbito, mas é dominado pelos pensamentos e emoções, onde, de fato, o objeto se torna objeto apenas através do discurso e se apresenta como tal apenas em sintonia com o discurso.

[...] Quando, portanto, o falante não tem a intenção de construir indeterminações ocultas, ou de cometer um erro com o intuito de enganar ou porque não estava atento, ainda assim ele poderá ser compreendido por aqueles com o mesmo nível de conhecimento da língua e da área, e no máximo apenas surgem diferenças irrelevantes no uso da língua. [...] Traduzir nesta área é, portanto, quase uma atividade mecânica [...] e nela existe pouca diferença entre melhor e pior, contanto que erros óbvios sejam evitados. (Schleiermacher, 1813)
\end{abstract}

Mas não é necessário, no entanto, recuar até o século XIX para encontrar conclusões do gênero. O filósofo espanhol Ortega y Gasset escreveu em 1937 que a tradução de textos técnicos seria algo concebível (ao contrário de textos literários), uma vez que esse tipo de texto não seria escrito em línguas naturais, sendo apenas um tipo de tradução para uma língua, de certa forma, artificial que Ortega y Gasset resume a terminologia, em outras palavras. Se o leitor desejar um exemplo mais recente, a excepcionalmente influente Enciclopédia Britânica (1974:22:583-4) informa em seu verbete sobre tradução que a tradução técnica é a única modalidade em que as ver- 
sões podem ser consideradas tão boas quanto o texto original. Apoiado neste argumento ad absurdum, o mesmo verbete finaliza com a constatação de que as traduções de textos literários são inferiores aos seus respectivos originais ou nem mesmo podem ser consideradas traduções "verdadeiras".

De fato, o debate acerca da tradução se caracteriza tradicionalmente, entre outros aspectos (Franco Aixelá, 2001), pela sua obsessão pelos textos canônicos. Aparentemente, apenas as traduções da Bíblia e de obras clássicas de grandes autores eram consideradas válidas para discussão (enquanto o restante era apenas "mecânico") dentro de uma atividade secundária como a tradução, uma área que, em seus primórdios, praticamente não era tratada com muita profundidade pelo mundo acadêmico.

Em consonância com essa linha de raciocínio, mesmo hoje em dia, com a exigência, por parte da Unesco, de incluir sempre o nome do tradutor em textos publicados, ainda é difícil encontrar nomes de tradutores técnicos em qualquer parte desses textos, principalmente em revistas científicas. Tal agravante reforça a tese da atividade mecânica, o que rebaixa o ofício dos tradutores técnicos para o mero fim de suporte técnico, um espelho linguístico sem qualquer influência no conteúdo, na percepção e no efeito do texto publicado, desde que, obviamente, tenham conhecimento da terminologia.

Paradoxalmente, ocorre o oposto quando se trata de pagamento, posto que a tradução técnica oferece remunerações bem mais altas do que as oferecidas pelo seu correspondente literário. A justificativa mais ou menos explícita (totalmente deduzida da lei da oferta e da procura) reside no número inferior de pessoas com capacidade de entender e traduzir um texto técnico, enquanto qualquer um seria capaz de entender e, portanto, de traduzir um texto literário (!!). Contudo, os tempos parecem mudar paulatinamente e, nos últimos anos (pelo menos na segunda metade do século $X X)$, é possível encontrar acadêmicos e profissionais que tentam chamar a atenção para a complexidade na função do tradutor técnico, em uma tentativa de lidar com essa aparente contradição. Por exemplo, Jumpelt alega que: 


\begin{abstract}
O presente estudo rebate a tese de que a prosa científica possa ser traduzida perfeitamente ou com mais facilidade [...]. O oposto é verdadeiro: os altos requisitos exigidos para traduzir textos técnicos se sobressaem perante outros gêneros, o que faz com que esse tipo de tradução se configure como uma área de pesquisa independente. Além das qualificações exigidas para uma boa tradução, a tradução científica ainda precisa respeitar tanto a função referencial da língua quanto as convenções da linguagem técnica, exigência esta que não se realiza em outros tipos de tradução na medida em que diz respeito a um conhecimento preciso do mundo (Jumpelt, 1961, p. 35).
\end{abstract}

A verdade é que a tradução técnica sempre representou o grosso dos textos traduzidos, principalmente no momento atual em que a troca de informações técnicas e a necessidade de intérpretes locais constituem uma parte essencial e definitiva das sociedades modernas pautadas pelos avanços tecnológicos. Finalmente, tais questões hoje se refletem nos cursos de graduação de Tradução em todo o mundo, deixando transparecer não apenas um maior peso atribuído à tradução técnica como parte de um esforço para no afã de adaptá-la às necessidades do mercado, mas também marca o início do deslocamento da tradução literária para o segundo plano na figura de uma disciplina opcional.

Além disso, o recente surgimento do estudo de línguas para fins específicos como disciplina acadêmica e, acima de tudo, da terminologia como uma subárea da linguística, ocasionou uma nova forma de olhar a complexidade e a estrutura desses novos tipos de textos e suas traduções. Em suma, parece que existe um crescente entendimento de que a tradução técnica merece mais atenção, mesmo que seja porque se trata do principal nicho profissional em que atuarão os estudantes universitários da área. Portanto, faz sentido explorar o estado da arte e descobrir como tudo se sucedeu e ainda se sucede nas cabeças dos pesquisadores.

Desse modo, o meu ponto neste estudo consiste em fornecer informações sobre o desenvolvimento da discussão sobre tradução técnica no âmbito de publicações específicas ao longo da história. Em outras palavras, como disse Jumpelt, trata-se de observar como e quando a tradução técnica e científica tornou-se uma "área de pesquisa com autonomia própria".

Com tal objetivo em mente, farei uso dos dados fornecidos pela BITRA (Bibliografia de Interpretação e Tradução), uma bibliografia online e gratuita (http://www.ua.es/dfing/tra_int/bitra_en.htm) que atualmente (se- 
tembro de 2003) abrange mais de 20.000 verbetes. Apesar da grande quantidade de dados, as informações que pretendo examinar serão obviamente incompletas. De fato, a incompletude é parte da natureza de qualquer ferramenta bibliográfica que pretende abranger tudo o que se publica em uma área em constante crescimento. E os números absolutos citados no presente estudo devem ser sempre considerados provisórios (de fato, os números deverão estar maiores em outubro de 2003). Uma possível tendência do banco de dados, que não deve ter tanta relevância no momento, é o fato de ser, antes de tudo, um projeto pessoal gerido por um professor espanhol em tradução para o inglês, o que significa que pode haver uma predominância de textos em inglês e espanhol. Ao longo desta pesquisa, gostaria de estimular pesquisadores, editoras e editores de periódicos a contribuir para a conclusão deste banco de dados, o que vai aumentar as chances de seus esforços não serem ignorados pela comunidade dos Estudos da Tradução No site em questão, há um sistema simplificado para inserção de novos verbetes ou resumos via e-mail. Contudo, ao passo que assumo a sua incompletude, devo ressaltar que a BITRA já é uma ferramenta bibliográfica representativa, responsável por dois terços das publicações existentes relacionadas (para evitar uma rima indesejada - "existentes" com "referentes") à nossa área interdisciplinar (baseado em minha própria estimativa de erros e acertos nas listas de referências que acompanham as publicações), tanto que as conclusões originadas deste fato deveriam fornecer uma estimativa exata do estado atual e histórico da discussão publicada sobre tradução. Entretanto, isso também significa que os números percentuais sempre serão mais confiáveis do que os absolutos, uma vez que aqueles possuem menor tendência de mudar com o aumento da quantidade de verbetes na BITRA.

Com a finalidade de auxiliar o leitor quanto às características de um texto técnico de acordo com a presente pesquisa, acrescento que a BITRA disponibiliza uma classificação em temas através de um sistema de descritores ou palavras-chave. No banco de dados, "técnico" é uma palavrachave que se aplica a publicações sobre tradução de qualquer texto ou tipo de texto em que haja uma terminologia específica pertencente a uma determinada área profissional ou acadêmica. As áreas mais comuns inseridas 
nesta categoria são "TI", "empresas", "medicina" e "jurídico", que também são palavras-chave. Contudo, qualquer texto ou tradução técnica não especificada (como, por exemplo, um título como Tradução Técnica e Científica) ou que lide com áreas específicas menos prestigiadas, como química ou assuntos militares, também são classificados como textos técnicos mesmo que não haja nenhuma palavra-chave específica, totalizando 1.905 verbetes categorizados como técnicos na BITRA de um total de 20.495 verbetes obtidos até setembro de 2003.

Vale ressaltar que a classificação temática utilizada pela BITRA é múltipla e simultânea, o que significa que um mesmo texto pode ser classificado ao mesmo tempo, por exemplo, como "Técnico" e "Automático", caso ambos os temas sejam centrais na publicação em questão (por exemplo, "Experimentos em Tradução Automática em Inglês-Espanhol de Dados Linguísticos Médicos"). Tal abordagem apenas evidencia como as coisas são e almeja realizar a busca mais completa possível. Todavia, não se pode deixar de lado o fato de algumas publicações pertencerem simultaneamente a duas ou mais categorias em nossa análise. Em alguns casos, por exemplo, o par técnico/Bíblia (cinco verbetes, incluindo duas palavraschave ao mesmo tempo) ou técnico/literário (26), serão bem raros, mas outros pares podem aparecer com mais frequência, como técnico/ensino (307).

\section{Um panorama global}

Conforme já apontado, temos 1.905 publicações $(9,3 \%)$ sobre tradução técnica diante de 4.314 verbetes (21\%) sobre tradução literária. Isso significa que o esforço acadêmico no campo literário da tradução é 2,3 vezes maior do que a discussão acerca de textos técnicos. Mesmo discussões sobre poesia, um gênero minoritário, faz frente aos debates sobre textos técnicos, equivalendo a dois terços do total de publicações técnicas com 1.275 verbetes $(6,2 \%)$. Isso remonta à questão acima mencionada que trata do foco tradicional dos Estudos de Tradução sobre canonicidade. Como diz Delabatista (1990:97):

As ciências sociais tendem a selecionar seus objetos de estudo de acordo com o seu prestígio cultural, e não necessariamente por interesse intrínseco. É comum considerar mais prestigioso estudar Shakespeare do 
que estudar literatura popular ou mesmo fenômenos decorrentes como as traduções. Os estudiosos da tradução, em geral, preferem estudar traduções de Shakespeare a traduções de uma telenovela.

E ele traz exemplos literários. De fato, parece que há uma escala que define o que tradicionalmente vale para uma pesquisa acadêmica. Antes de tudo, temos uma ideia romântica de que o estudo dos originais é superior aos de suas traduções, mesmo que determinado autor tenha adquirido proeminência em alguma outra língua através da tradução (na verdade, mesmo que o pesquisador em questão estude tal autor através de suas versões na sua língua materna, tanto que as conclusões são derivadas das traduções e não do texto original). Tradução é, portanto, uma atividade secundária (derivada) e invisível, e o gênero técnico, tradicionalmente com menos prestígio cultural em termos de linguagem e estilo, é ainda menos interessante se for estudado sob a ótica de suas respectivas traduções. Mas isso é apenas uma visão antiquada - ou será que não é?

Observemos a evolução das 1.905 publicações sobre tradução técnica em comparação ao restante. Farei a divisão do tempo em dois grandes períodos: antes de 1950 (antes de 1900 e entre 1901 e 1950) e, a partir daí, por décadas até o ano 2000. A razão para tal divisão é meramente uma questão de disponibilidade. Entre, por assim dizer, o "início dos tempos" e 1900, temos 259 verbetes (sempre coletados da BITRA até setembro de 2003) sobre tradução, enquanto que, entre 1901 e 1950, esse número chega a 340. Não faria muito sentido e seria bem tendencioso dividir esses períodos em décadas. Após a Segunda Guerra Mundial, o panorama dos Estudos da Tradução muda por completo e, entre 1951 e 1960, temos 596 verbetes, enquanto que, entre 1991 e 2000, esse número chega a um total de 10.450, fornecendo números em que o peso proporcional de trabalhos individuais excepcionais não pode trazer um novo viés à análise. O período entre 2001 e 2002 não é detalhado no presente estudo por duas razões: primeiramente, trata-se de um período muito curto para ser comparado de forma significativa com as estatísticas de décadas passadas; em segundo lugar, as informações referentes às novas publicações geralmente demoram a aparecer e muitos verbetes ainda serão adicionados a esse período de dois anos até que possam ser considerados razoavelmente representativos. 
Antes de continuar a análise das contribuições sobre tradução técnica de forma detalhada, segue abaixo uma tabela com a evolução quantitativa e proporcional dos trabalhos feitos acerca deste tipo de tradução:

Fonte: BITRA, setembro de 2003

Total de verbetes em Trad. Técn. \& Cient. \& Trad. Cient.

(em números absolutos) $(\%)$

Até 190025900

1901-1950 $34051.4 \%$

$1951-1960596386.4 \%$

$1961-1970761597.7 \%$

1971-1980 1.594 $1197.5 \%$

$1981-19904,8303727.7 \%$

1991-2000 10,450 1,071 10.2\%

Todos os anos 20,495 1,905 9.3\%

(incl. 2001-2003)

\section{Até $\mathbf{1 9 0 0}$}

Antes do ano de 1900, o número de publicações sobre tradução técnica reunidos na BITRA é zero de um total de 259 verbetes. Com exceção de um ou outro manual (não podemos esquecer que a tradução era uma ferramenta fundamental para o ensino de língua estrangeira antes da chegada dos métodos comunicativos) e alguns trabalhos específicos como os de Tytler (1791, 1813), a maioria dos textos listados compreende reflexões/apologias sobre métodos específicos de tradução. Trata-se, em geral, de pequenos textos dispostos como prefácios, digressões ou cartas justificando traduções individuais (o que é o caso de quase todas as citações tradicionais na história da tradução, de São Jerônimo a Humboldt). Naturalmente, por questão de acessibilidade, este período é provavelmente o menos completo no banco de dados, ainda que compreenda atualmente mais que 250 verbetes e que nenhum deles trate de tradução técnica. Não parece que há muito a ser 
FRANCO AIXELÁ, O Estudo de Tradução Técnica e Científica

Traduzido por VIEIRA

dito quanto ao papel da reflexão acerca da tradução técnica e científica no período anterior a 1900.

\section{4. $1901-1950$}

Entre 1901 e 1950, temos cinco verbetes (1,4\%) sobre tradução técnica de um total de 340 publicações correspondentes a este período na BITRA. A primeira remonta a 1925 e é um artigo de sete páginas escrito por Charles Homer Haskins sobre "A Ciência Árabe na Europa Ocidental." Como se pode deduzir pelo tamanho do artigo e seu título, essa reflexão inicial é histórica e dificilmente abordará as complexidades ou a natureza da tradução técnica. O mesmo ocorre no segundo verbete, o artigo "Sobre a Transmissão da Ciência Grega e Indiana para os árabes" (1937), de Max Meyerhof. Em seguida, temos um artigo de caráter profissional (extremamente moderno para a época) em "Le travail et les aptitudes des interprètes parlamentaires" (o trabalho e as aptidões dos intérpretes parlamentares), escrito por J. Sainz em 1931; um artigo sobre “Dicionários de Tradução Técnica" de A. L. Gardner (1950); e uma cartilha de 62 páginas de diversos autores denominada "Tradutor, Espanhol e Francês. Testes Preparatórios para os Exames do Serviço Público", publicada em Milwaukee (Wisconsin) em 1942.

Os outros 335 verbetes trazem a tradução da Bíblia (84 verbetes $24,7 \%$ ) e a tradução literária (102 - 30\%) como tópicos principais, o que denota certa diferença em relação à porcentagem referente aos textos técnicos. Embora estudos históricos (126 verbetes - 37\%) sobre a recepção de autores canônicos e críticas exegéticas sejam os temas mais recorrentes (com títulos como A Bíblia nas Versões Antiga e em Inglês ou Traduções de Textos Clássicos para o Inglês de Caxton até Chapman, 1477-1620), passamos a encontrar algumas abordagens teóricas sobre a natureza da tradução conduzidas por autores como Walter Benjamin (1923), Ortega y Gasset (1937) ou Nida (1947). Praticamente todos ignoram a questão da tradução técnica ou, no máximo, fazem alguns comentários ligeiros quanto a sua natureza basicamente mecânica.

Ao fim da primeira metade do século 20, já se pode dizer que o inglês se torna, de forma um tanto inesperada, a língua franca também na 
área da teoria da tradução, com 229 publicações nessa língua (67\%), enquanto outras "línguas científicas importantes", como francês, alemão ou espanhol, se encontram na margem de 30 a 40 verbetes (cerca de 10\%). Minha própria posição de professor espanhol de tradução em língua inglesa provavelmente reforça a tendência da distribuição linguística da BITRA, mas, de qualquer forma, as diferenças entre as línguas não parecem ser muito significativas para negar que tal fenômeno seja uma tendência real.

\section{5. $1951-1960$}

A década de 1950 foi marcada pelo aumento significativo de publicações sobre tradução ${ }^{2}$, com algumas abordagens inéditas e influentes para a tradução profissional, como os trabalhos de Vinay e Darbelnet (1958). O crescimento se multiplica por dez, chegando a 536 verbetes, que equivale a quase 60 publicações por ano, em contraposição a menos do que sete publicações por ano em meio século entre 1901 e 1950, sem contar o período anterior ao século 20. Nessa década, uma nova disciplina corresponde a, no mínimo, 15\% dos novos interesses: a tradução automática, com 89 verbetes, evidenciando o nascimento de um tempo em que a tradução se torna uma atividade de crescimento exponencial associada à expectativa de que os computadores, por si, seriam capazes de fazer esse trabalho. Ao que tudo indica, esse interesse repentino pela tradução automática chegou a superar o tradicional foco em tradução literária (79 verbetes, ou 13,2\% para esse período na BITRA), sendo apenas superado por outro tópico tradicionalmente querido pelos teóricos da tradução: a tradução da Bíblia, com 200 verbetes $(33,5 \%)$. Este último número se deve em grande parte à existência de um periódico especializado, O Tradutor da Bíblia (171 verbetes nos anos cinquenta) que, até onde eu saiba, foi o primeiro - e por muito tempo o único - periódico especializado na teoria e na prática da tradução até o lançamento das revistas Babel em 1955 e Meta em 1956. Abordagens históricas permanecem representando boa parte da pesquisa, com 65 verbetes $(10,9 \%)$.

\footnotetext{
2 Não ainda na área de interpretação, que contava com apenas duas publicações. Curiosamente, no entanto, ambas as publicações lidavam com interpretação técnica, com um livro sobre interpretação em tribunais (Gion Sing Sia, 1954) em um contexto colonial, e um pequeno artigo sobre intérpretes militares (Kurt Jr. Vonnegut, 1955).
} 
De um total de 596 verbetes, a tradução técnica aparece como tema em 38 (26 artigos, três capítulos e nove livros), evidenciando outro aumento significativo não apenas em números absolutos, mas também no que se refere às porcentagens com surpreendentes $6,4 \%$, o que aponta para o início de um novo interesse nos Estudos da Tradução.

Um olhar mais atento na distribuição temática desses 38 verbetes permite observar se as diferenças quantitativa e qualitativa se encontram em sintonia. A resposta é positiva, mas com ressalvas: temos nove verbetes de assuntos relacionados apenas em parte à teoria e à prática da tradução técnica, contando com títulos como o texto de Holmstrom (ed.) de 1957, Tradução Técnica e Científica e Outros Aspectos do Problema da Linguagem ou diversos trabalhos de Rudolf Walter Jumpelt como "Abordagens Metodológicas para a Ciência da Tradução" (1959)³. Textos como esses parecem evidenciar um desejo em transcender o instrumentalismo puro e embarcar nos estudos deste gênero da tradução com certa profundidade, em uma tentativa de estabelecer uma nova abordagem digna de ser classificada como pesquisa científica. Da mesma forma, a terminologia e o estudo das línguas para fins específicos ainda não eram disciplinas acadêmicas de importância e boa parte dos verbetes que obtemos nessa década refletem uma abordagem bem prática, focada em questões como os melhores dicionários especializados (por exemplo, o texto Estudo dos Dicionários Interlinguíticos Científicos e Técnicos, de Holmstrom (1951)) ou profissões (por exemplo, "Serviços de Tradução Técnica", de Kalé (1956)). No mesmo período (1959), temos o primeiro trabalho do pesquisador prolífico Henri van Hoof registrado na BITRA ("Reflexões sobre a linguagem médica. O ponto de vista do tradutor científico").

Como mencionei acima, esse período também testemunhou o lançamento de dois periódicos essenciais para a história dos Estudos da Tradução: Babel (1955) e Meta (1956). A existência de periódicos especializados e ávidos por teoria evidencia um sintoma e uma causa. Sintoma porque a simples existência dessas publicações, de um amplo público leitor e sua

\footnotetext{
${ }^{3}$ Ambos têm pelo menos cinco publicações neste período, sendo os pioneiros nesta área dos Estudos da Tradução.
} 
sobrevivência por tantas décadas indicam que ainda há um interesse específico pelos Estudos da Tradução, com tantos departamentos de línguas solicitando a assinatura de tais periódicos, os quais trabalharam com um tema então considerado secundário demais para ser digno da atenção dos acadêmicos (sem falar de um periódico especializado em particular, também sobre tradução técnica, cujo primeiro periódico específico nasce aqui e agora, em 2003). É também uma causa pelo simples fato de tais periódicos fornecerem uma plataforma acadêmica inédita para uma área de pesquisa em crescimento que até então não tinha o seu próprio espaço acadêmico e se encontrava perdida em meio a periódicos científicos ou sobre linguística e literatura. A partir dali, surge um nicho para a área da tradução, um espaço acadêmico de prestígio para o trabalho de estudiosos que certamente serão lidos por pessoas com interesse genuíno nesta nova área de pesquisa, o que claramente multiplicou o seu escopo de investigação.

Babel, o periódico da FIT (Federação Internacional de Tradutores), é responsável por quase metade (16) das publicações registadas na BITRA no período entre 1951 e 1960. Babel é um periódico histórico que contribuiu de forma significativa para o desenvolvimento dos Estudos da Tradução, principalmente no que concerne a questões práticas e profissionais da área, com pelo menos 49 artigos sobre tradução técnica e científica em toda a sua história. Contudo, devido à escassez de periódicos sobre tradução, a revista Babel também teve que abranger pesquisa teórica "pura", o que a fez transcender a sua função inicial de periódico preocupado com o aspecto profissional.

Outro periódico nascido neste mesmo período (1956) foi a revista Meta, publicada pela Universidade de Montreal e acessível pela internet desde o volume 11 (1966), razão pela qual a BITRA ainda não contém verbetes referentes aos primeiros dez anos. A Meta é outro periódico histórico especializado amplamente lido em nossa área de concentração. Sempre demonstrou um interesse acentuado em terminologia (principalmente do francês para o inglês) e, uma vez se tratar de um periódico universitário, volta-se também para aspectos relacionados ao ensino. Tais fatores explicam os 345 artigos sobre tradução desse tema específico. 
Dentre as publicações da década de 1950, é válido ressaltar a presença significativa da língua russa, o que reflete a notória presença do cenário geopolítico em meio a Guerra Fria. Com esse pano de fundo, todos os textos são naturalmente centrados na tradução do russo para o inglês, tais como "Estudos de Engenharia e Linguística na Tradução Automática: Relatório Técnico" (1958), mesmo preparado "para o Centro de Desenvolvimento Aéreo do Laboratório de Inteligência de Roma, Base Aérea da Griffis, Nova York, pelo Departamento de Línguas e Literaturas Orientais e Eslavas e pelo Departamento de Engenharia Elétrica da Universidade de Washington. Contrato AF 30(602)-1827."

Também vale destacar o período em que o inglês já se configura, de longe, como a língua dominante na pesquisa de tradução, incluindo o estudo de tradução técnica, com 452 (75,8\%) publicações em inglês contra 68 $(11,4 \%)$ em francês, 38 (6,4\%) em alemão e 22 (3,7\%) em espanhol. Dentro da área específica de tradução técnica, de um total de 38 verbetes, 29 são em inglês (76,3\%). Francês e alemão vêm logo atrás, com quatro $(10,5 \%)$ e três $(7,9 \%)$ textos, respectivamente.

Este fato, que será confirmado em nível global em nossa pesquisa nos últimos anos, é um sinal de que os Estudos da Tradução, ao menos no que concerne a esta questão, não é diferente de outras disciplinas científicas. Ainda que a natureza do tema pressuponha um campo de pesquisa multilíngue e equilibrado, a demanda de leitura e a natureza de língua franca do inglês desde a Segunda Guerra Mundial faz com que os artigos científicos (como este que estou escrevendo agora) prefiram o inglês a suas respectivas línguas maternas, com o fim de obter uma recepção ainda mais ampla.

\section{6. $1961-1970$}

O período entre 1961 e 1970 evidencia, mais uma vez, um crescimento notório, com um total de 761 verbetes, sendo 59 sobre tradução técnica, novamente registrados na BITRA até setembro de 2003. A proporção dos artigos baseados em tradução técnica agora constitui 7,7\%, com tradução literária (132 verbetes - 17,3\%) e tradução bíblica $(133$ - 17,4\%) liderando, como sempre, e constituindo mais de um terço das publicações, embora tives- 
se diminuído quase pela metade na década anterior. Textos sobre questões históricas da tradução ainda possuem a sua devida importância, mesmo que pareçam perder peso com 59 verbetes $(7,7 \%)$.

O predomínio da tradução automática perdura, pelo menos, até a publicação do famoso relatório do ALPAC (Comitê Assessor de Processamento Automático de Língua - Conselho Nacional de Pesquisa [E.U.]) de 1966, o qual concluiu que a tradução interlingual feita por computadores, se de fato possível, ainda estava longe de ser algo concreto. De qualquer forma, a tradução automática ainda representa $6,4 \%$ do total de verbetes, e veremos também que o interesse acadêmico na área se restaurará motivado simplesmente pela necessidade econômica, apesar das expectativas menos ambiciosas quanto ao seu desempenho. Mesmo assim, não será nada comparável com a pesquisa da área literária. Importa ressaltar que, na década de 1950, há mais verbetes sobre tradução automática do que sobre textos literários.

Essa década também testemunha a produção essencial dos pioneiros da área da Linguística na teoria da tradução, como Eugene A. Nida, Georges Mounin ou John C. Catford. Os trabalhos desses autores, em meados do século vinte, foram fundamentais, focando em questões relativas à tradução como equivalência, traduzibilidade e linguística contrastiva. Todas essas linhas de pesquisa ainda despertam o interesse de muitos autores, ainda que o ramo mais teórico da área autônoma de Estudos da Tradução pareça estar centrado atualmente em outros aspectos, como o papel histórico e atual da(s) tradução (ões) e dos tradutores e a imagem "do outro" que esses transmitem.

Os 59 verbetes (48 artigos, oito livros, dois capítulos e uma tese de doutorado) sobre tradução técnica evidenciam o destaque dado a aspectos teóricos gerais com onze verbetes $(18,6 \%$ do total sobre tradução técnica) que poderiam ser classificados como "reflexões gerais" (por exemplo, o artigo de Horguelin de 1966, intitulado "La traduction technique" [A tradução técnica] ou o capítulo publicado por Cunningham em 1970, denominado "A Interação entre os Tradutores Técnicos e Literários"). Aspectos práticos, principalmente no que tange a terminologias do par InglêsFrancês da revista Meta (como o artigo "Vocabulaire des assurances socia- 
les" [Vocabulário da seguridade social] publicado em 1967 por Grandpré) ou outras publicações que discutam tipos específicos de textos ainda representam a essência do interesse de pesquisadores, com 32 (54\% dos verbetes técnicos) publicações deste gênero.

De fato, a revista Meta foi fundamental para alavancar a publicação de textos sobre tradução técnica nesse período, contando com $40(67,8 \%)$ dos verbetes na época. Esses números também representam uma porcentagem significativa do número total de artigos publicados pelo periódico canadense para o período (40 de 111, ou seja, 36\%) e claramente demonstram sua vocação para a área prática, ainda mais com a sua tentativa de preencher lacunas terminológicas no par de línguas Inglês-Francês. Por alguma razão, a revista Babel reduz de forma significativa seu interesse nesse tipo de tradução, com apenas quatro artigos de 49. É verdade que boa parte dos artigos da Meta estão incluídos na BITRA para este período, enquanto muitos artigos da Babel não o foram, mas não se previa uma mudança significativa nas proporções uma vez que o processo de compilação de verbetes não possui uma tendência determinada. De qualquer forma, o fato de que mais de dois terços dos verbetes sobre tradução técnica venham de um periódico especializado (quase $75 \%$ se incluirmos a $\mathrm{Babel}$ ) claramente confirma o papel fundamental desempenhado por essas publicações. Se não as levarmos em conta, a pesquisa em tradução dependeria enormemente de disciplinas coirmãs, como a linguística, a história e os estudos literários, que possuem focos diferentes e impõem limites a contribuições que não são centrais para os seus objetivos.

As principais áreas da pesquisa em tradução, conforme determinado pelos tipos de texto técnico, começam a se estabelecer nesse período com seis verbetes sobre tradução médica, oito sobre textos jurídicos, onze sobre textos de negócios e alguns (ainda nos anos sessenta) sobre textos de tecnologia da informação.

O panorama não é muito distinto na distribuição de línguas, com 387 (50,8\%) em Inglês, 200 (26,2\%) em francês, 115 (14,4\%) em alemão e 44 $(5,8 \%)$ em espanhol. É verdade que a língua francesa possui maior representação nesse caso, o que pode ser explicado novamente pela produção considerável de periódicos especializados que fomentam as contribuições 
em francês, como Meta (e Babel em menor extensão). De fato, quase metade das publicações em francês provém diretamente da Meta. Essa política de promoção do uso da língua francesa (92 artigos em francês e 19 em inglês para o período) partindo da Meta, junto a diversas contribuições sobre tradução técnica, ajudam a explicar a contradição entre as línguas geralmente utilizadas e a língua majoritária da década em questão ao analisar apenas as publicações sobre tradução técnica. Portanto, 45 de 59 (76,3\%) verbetes sobre tradução técnica estão em francês, dos quais 40 são da Meta, que não publicou nada em inglês na década de 1960. Dos outros catorze verbetes não oriundos da Meta, a hegemonia é, mais uma vez, devolvida à língua inglesa, com onze verbetes nesta língua das mais variadas fontes.

\section{7. $1971-1980$}

Essa década, junto aos anos oitenta, pode ser considerada o ponto de partida para a constituição dos Estudos da Tradução como uma disciplina autônoma, em virtude de pesquisas de referência realizadas por autores pioneiros na área como James S. Holmes, Gideon Toury, Wolfram Wilss, Albrecht Neubert, George Steiner, Hans J. Vermeer, Katharina Reiss, entre outros. Isso também se refletiu no aumento significativo de trabalhos com foco em tradução, com 1.594 verbetes obtidos na BITRA (até setembro de 2003), dobrando a produção da década de 1960, iniciando o que poderia ser denominado como a "Era de Ouro" dos Estudos da Tradução ao longo das últimas décadas do século vinte. Para se ter uma ideia do crescente interesse em tradução e interpretação verificado nesse período, basta mencionar os cerca de cinco mil verbetes dos anos oitenta e os mais de 10.000 nos anos noventa, além do número de periódicos especializados ter aumentado de menos de dez para mais de setenta na atualidade, sendo boa parte focado nos Estudos da Tradução.

Mais uma vez, a tradução de textos literários (299 verbetes - 18,7\%) e da Bíblia (240 - 15\%) representam a maior parte da produção relacionada a esses anos. Tradução automática corresponde a 75 verbetes $(4,7 \%)$, número que confirma o baixo interesse por esse tipo de tradução, que agora deixa de ser visto como algo eminentemente prático ou mesmo uma solução possível para os problemas da tradução. Outras questões como a história 
da tradução (197 - 12,3\%) e tradução profissional (112 - 7\%) permanecem se desenvolvendo em nossa disciplina, ainda caracterizada por sua variedade. Interpretação, por sua vez, permanece na busca pelo seu próprio nicho dentro dos Estudos da Tradução com 96 verbetes (6\%), quatro dos quais tratam da tradução do discurso técnico. Finalmente, aspectos relacionados ao ensino passam a refletir em novos cursos de graduação de tradução e interpretação, ainda representando consideráveis $11,2 \%$ com 178 verbetes.

Quanto às línguas representadas, o inglês permanece dominante com cerca de metade das publicações, abrangendo 719 verbetes $(45,1 \%)$, seguido por francês, com $460(28,8 \%)$, enquanto outras línguas vêm bem atrás (alemão tem 15,3\%; espanhol 6,5\%; russo 2,9\%; italiano 2\%; e assim por diante).

Publicações sobre tradução técnica também dobraram em números absolutos nesta década, com 119 verbetes (7,5\%), o que basicamente corresponde - e isso é o que realmente importa na análise da função da tradução técnica dentro dos Estudos da Tradução - à mesma proporção da década passada. A revista Meta ainda exerce bastante influência e seu poder de penetração é tão grande quanto nos anos sessenta, com 78 (65\%) dos verbetes sobre esse tipo de tradução, oriundos do periódico canadense. Com foco em textos técnicos, esse periódico tradicionalmente publicado em francês, novamente apresenta uma distorção na proporção das línguas, com 88 verbetes $(74 \%)$ em francês, 71 oriundos diretamente da Meta (com apenas sete artigos técnicos escritos em inglês). Curiosamente, a revista Babel parece focar em aspectos teóricos nesse período e apenas dois artigos (dos 34 incluídos na BITRA) sobre tradução técnica. De qualquer forma, 23 verbetes $(19,3 \%)$ sobre tradução técnica são escritos em inglês e, se excluirmos os artigos oriundos da Meta, a língua inglesa representa 15/41 (36,6\%), o que se aproxima de forma significativa da proporção geral.

No tocante aos temas sobre os quais versam esses 119 verbetes, a primeira observação a se fazer é que um dos principais objetivos da Meta é oferecer terminologias do par inglês-francês para todas as áreas técnicas possíveis através de artigos como "Terminologie des grades universitaires (3e partie et fin) [Terminologias dos diplomas universitários $\left(3^{\circ}\right.$ parte e 
final)] de Henry (1971) ou a contribuição de Couture "Quelques termes de soudage" [Termos referentes à soldagem] de 1972. São artigos indubitavelmente interessantes e práticos, apesar de não representarem uma tendência significativa nos interesses centrais dos Estudos da Tradução, mesmo inseridos na área específica de discussão sobre tradução técnica. Contudo, é perfeitamente compreensível que um periódico canadense sobre tradução tenha como uma de suas principais metas abordar questões relacionadas à terminologia do par francês-inglês, mesmo que tais questões sejam secundárias para outros periódicos sobre tradução publicados em países multilíngues como Espanha e Bélgica.

Uma questão bem relevante, nos anos setenta, para o reconhecimento da importância da tradução técnica e científica foi o surgimento das primeiras bibliografias especializadas. Trabalhos desse gênero, naturalmente, apenas fazem sentido na medida em que há material suficiente para listar e comentar. É verdade que listas bibliográficas com foco na tradução de línguas específicas precisam apenas incluir um número suficiente de livros e obras lexicográficas de referência, principalmente dicionários (existem pelo menos três publicações sobre dicionários técnicos anteriores a 1971, como o artigo de Gardner de 1950 “Dicionários de Tradução Técnica”). Entretanto, também é verdade que ferramentas bibliográficas apenas são publicadas, quando se considera a sua necessidade e a grande diferença aqui é que estamos falando de publicações que incluem trabalhos sobre a natureza e as estratégias empregadas nesse tipo de tradução (caso contrário, não seriam descritos na BITRA como "Bibliografia" e, sim, como "Documentação"). Nos anos oitenta, duzentas obras ainda aguardavam para ser listadas, sem contar dicionários ou obras sobre escrita científica em geral que normalmente são incluídas nessas bibliografias. Portanto, só agora é que se percebe a existência de um número razoável de publicações sobre tradução técnica em geral e em áreas específicas para justificar a tentativa de reuni-las numa lista. Temos cerca de seis verbetes na BITRA, como o artigo "Bibliographie de la traduction médicale" [Uma bibliografia sobre tradução médica] publicado em 1974 por Hoof ou o livro Bibliographie sélective du traducteur. Commerce et économie [Uma bibliografia para o tradutor. Comércio e economia], publicado em 1977 por Gémar e Horguelin, ambos eviden- 
ciando a importância da Universidade de Montreal na sistematização da tradução técnica.

Por outro lado, essa década observa uma consolidação das tendências preexistentes. Talvez a mais significativa seja a tendência majoritária e pragmática de comentar sobre questões específicas em tipos específicos de texto. Portanto, temos 29 verbetes sobre tradução de textos jurídicos, dezoito da área de negócios, seis sobre medicina, dois sobre TI e 26 sobre assuntos diversos, totalizando $80(67,2 \%)$ do total de verbetes sobre tradução técnica. Parece evidente que esse ramo dos Estudos da Tradução sempre se caracterizou maciçamente por uma vertente pragmática, e esse aspecto parece lógico quando se considera as necessidades específicas de tradutores e aprendizes que exercem essa atividade.

\section{8. $1981-1990$}

Mais uma vez, observa-se um aumento expressivo do número de publicações na medida em que nos aproximamos dos tempos atuais. As 1.594 publicações dos anos setenta agora passaram para 4.830, e as 119 sobre tradução técnica agora são 372 nos anos oitenta, apesar da proporção $(7,7 \%)$, e o peso relativo deste tipo de texto no aparato geral dos estudos da tradução, permanecer praticamente no mesmo patamar do período entre os anos sessenta e noventa.

A distribuição de publicações nos anos oitenta apresenta mudanças significativas em relação às décadas anteriores. Temos 439 verbetes $(9,1 \%)$ sobre tradução da Bíblia logo no início. Apesar de ainda possuir certa importância em termos qualitativos, essa área parece ceder a sua posição nuclear com o surgimento de novas áreas de orientação acadêmica e profissional, como aspectos profissionais (286 verbetes - 5,9\%) e ensino, uma constante que permanece até alcançar os atuais 684 verbetes $(14,2 \%)$, sem falar do tradicional interesse em história da tradução (684 verbetes - 13,4\%) ou em temas literários, o que mantém a margem tradicional com 1.000 verbetes $(20,7 \%)$. Tradução automática atrai o interesse de 355 verbetes $(7,3 \%)$, sendo ainda uma área importante dentro de nossa disciplina. A área de Interpretação, por sua vez, mantém sua tendência ascendente rumo ao pro- 
FRANCO AIXELÁ, O Estudo de Tradução Técnica e Científica

Traduzido por VIEIRA

tagonismo nos Estudos de Tradução, partindo dos 6\% nos anos setenta aos $9,8 \%$ (476 verbetes) na atual década.

A língua inglesa permanece predominando com 2.359 verbetes $(48,8 \%)$, estando, de certo modo, distanciada do francês (1.085 - 22,5\%), do espanhol (621 - 12,8\%) e do alemão (595 - 12,3\%), com outras línguas bem atrás (italiano e russo, por exemplo, mal atingem 1,5\% com 71 verbetes cada). Mais uma vez, a atuação fundamental da revista Meta na área de tradução técnica distorce esses números, contribuindo com 154/372 verbetes em francês (41,4\%) em comparação a 137 (36,8\%) em inglês, e 40 (10,7\%) em espanhol e em alemão. Se não levarmos em conta artigos publicados no periódico canadense, os números seriam 58 em francês e 119 em inglês numa correspondência quase perfeita com a distribuição geral de línguas para este período.

Quanto à distribuição de 372 verbetes sobre tradução técnica, percebe-se uma continuidade das tendências já existentes nos anos setenta. Portanto, temos 95 verbetes $(25,5 \%)$ sobre tradução de textos jurídicos e interpretação, uma área que adquire cada vez mais força e vem se tornando um claro domínio específico de destaque dentro da área da tradução técnica. Tradução médica e de negócios permanecem com um perfil razoavelmente elevado, com $37(9,9 \%)$ e $30(8 \%)$ verbetes, respectivamente, enquanto a tradução de TI pareceu crescer um pouco com 19 verbetes $(5,1 \%)$. Aspectos relacionados a ensino passam a desempenhar um papel muito importante como um todo, com 56 verbetes $(15 \%)$ do total de contribuições na área técnica, 18 dos quais correspondem a manuais direcionados em parte para fins universitários. Outros temas de caráter prático, como aspectos profissionais (22 verbetes - 5,9\%) e documentação $(40-10,7 \%)$ ainda representam uma proporção significativa da dedicação de pesquisadores. Finalmente, o crescimento, como um todo, do interesse em interpretação também se evidencia nessa área, com 46 (12,4\%) sobre discurso técnico, mais que a metade sobre linguagem jurídica e administrativa.

\section{1991-2000}

Na última década do século vinte, novamente se duplica a produção acadêmica publicada na área de Estudos da Tradução. Temos, portanto, não 
FRANCO AIXELÁ, O Estudo de Tradução Técnica e Científica

Traduzido por VIEIRA

menos que 10.450 verbetes (4.830 nos anos oitenta), $1.071(10,2 \%)$ dos quais tratam sobre tradução técnica (372 - 7,7\% nos anos oitenta), evidenciando um aumento proporcional que parece ser estatisticamente significativo pela primeira vez em quarenta anos.

A literatura, como de costume, atrai o maior interesse dos pesquisadores, com 2.333 verbetes (22,3\%), enquanto outro tema de cunho tradicional, a tradução da Bíblia (423 verbetes - 4\%) continua a perder terreno consideravelmente. Temas relacionados ao ensino, por sua vez, parecem finalmente ter alcançado uma posição estável na área de Estudos da Tradução com 1.448 verbetes (13,9\%), ultrapassado apenas pela área da literatura. Tradução automática continua a exercer um papel secundário, porém significativo, com 733 verbetes (7\%). Interpretação continua a ser um importante ramo da área mesmo parecendo perder terreno de forma inesperada em comparação aos anos oitenta, incluindo 794 verbetes $(7,6 \%)$ na BITRA para os anos noventa. Finalmente, o crescimento dos Estudos da Tradução significa que outros temas que até então haviam sido ignorados no âmbito da pesquisa acadêmica passam a atrair a atenção de estudiosos. É o caso, por exemplo, da tradução audiovisual, com 452 verbetes $(4,3 \%)$ nos anos noventa se comparado com $1,3 \%$ nos anos oitenta ou $0,7 \%$ nos anos setenta.

O uso do inglês permanece predominante com cerca de metade das publicações, totalizando 5.014 verbetes $(48 \%)$, seguido por espanhol (2.349 - 22,5\%), francês $(1.575$ - 15,1\%) e alemão (1.039 - 9,9\%) como línguas majoritárias. Não ouso dizer que espanhol começa a crescer tanto na área de Estudos da Tradução. Como já disse previamente, em virtude de minha própria condição de falante de língua espanhola, é natural imaginar que terei mais facilidade em acompanhar a produção acadêmica de meu próprio país, a ponto de haver uma proporção acima da média de trabalhos em espanhol na BITRA. Ao mesmo tempo, não posso deixar de mencionar que, apesar de a primeira instituição de língua espanhola a prover treinamento profissional de tradução (a Universidade Autônoma de Barcelona) tenha sido fundada apenas em 1972, o crescimento exponencial desta área resultou em cerca de dezessete cursos universitários de tradução na Espanha, um dos países com maior concentração de cursos do gênero no mundo, o 
que equivale a maior número de conferências e mais periódicos, dos quais ao menos dezesseis utilizam o espanhol como primeira língua.

Nesse aspecto, um exemplo da proporção aparentemente crescente de autores de língua espanhola nos Estudos da Tradução poderia ser percebido a partir de um periódico internacional como Babel. Se considerarmos o período entre 1985 e 1990, temos 2/84 (2,3\%) de autores de língua espanhola, mas, se considerarmos o período entre 1995 e 2000, temos 20/98, que corresponde a $20,4 \%$ com um pico surpreendente de $7 / 17$ no ano 2000 . Nesse caso, uma parte considerável das contribuições acadêmicas desses autores é escrita em inglês que, naturalmente, também escreveram boa parte de suas próprias produções em espanhol. É possível que essa presença cada vez maior da língua espanhola nos Estudos da Tradução esteja, de fato, em ascensão.

No que concerne à distribuição linguística dentro da tradução técnica, o panorama se altera completamente em comparação às décadas anteriores em virtude do arrefecimento da extraordinária influência antes exercida pela Meta. Como pudemos observar, os números absolutos relacionados às publicações sobre tradução técnica se duplicaram nessa década, enquanto a Meta publica um número ligeiramente menor de artigos sobre esse tipo de tradução (75 nos anos noventa) e uma proporção maior (25/75) é escrito em inglês. De qualquer forma, a influência desse periódico na distribuição linguística de verbetes sobre aspectos técnicos se reduz drasticamente, evidenciando um panorama linguístico muito próximo do geral, com 447 verbetes (41,7\%) em inglês, 185 (17,3\%) em francês, 84 (7,9\%) em alemão e 313 $(29,3 \%)$ em espanhol. Mais uma vez, a última apresenta uma porcentagem, à primeira vista, parece excessiva. Portanto, houve um aumento proporcional considerável (nos anos oitenta, o espanhol se encontrava, como o alemão, por volta dos $10 \%$ ) enquanto nosso método de reunir registros não se alterou. Apesar de a BITRA ser baseada na Espanha e a suposta parcialidade que isso envolve, ouso dizer que o peso do espanhol nos Estudos da Tradução, sem dúvida, encontra-se em franco desenvolvimento, de certo modo, devido às questões acadêmicas acima mencionadas.

Se observarmos a distribuição dos 1.067 verbetes sobre tradução técnica, percebe-se que não ocorre nenhuma mudança nos anos oitenta. 
Temos 333 verbetes $(31,2 \%)$ sobre tradução de textos jurídicos, parecendo adquirir cada vez um predomínio na área. Em comparação, a tradução na área médica possui 189 verbetes (17,7\% dos verbetes sobre tradução técnica), tradução de textos referentes ao universo corporativo possui $71(6,6 \%)$ e tradução de TI tem 89 (8,3\%), o último demonstrando um crescimento importante que pode ser explicado, de certa forma, se considerarmos que muitos dos verbetes tratam dos novos fenômenos acadêmicos da localização. O interesse pelo ensino de tradução técnica, como esperado, permanece crescendo de forma vagarosa, porém firme, resultando em 185 verbetes $(17,3 \%)$ nos anos noventa sobre o tema, incluindo 46 manuais. A interpretação do discurso técnico também continua a atrair uma importante parcela de interesse com 124 verbetes (11,6\%). Nesse caso, aspectos jurídicos e administrativos (com interpretação comunitária figurando como um tema inédito) novamente representam bem mais da metade dos verbetes, com 92/124 (74,2\%). Como podemos observar, a abordagem permanece basicamente de caráter prático, de uma forma geral, contando com outros aspectos "não acadêmicos" como questões profissionais (94 verbetes $-8,8 \%$ ) e documentação (116 - 10,8\%), desempenhando funções importantes nessa área. Contudo, podemos também encontrar publicações que objetivem uma perspectiva mais global, como a palestra proferida por Durieux em 1991 intitulada "La créativité en traduction technique" [A criatividade na tradução técnica], ou o artigo de 1997 escrito por Steyaert em Janssens denominado “Linguagem e Tradução em um Contexto de Negócios Internacionais: Além de uma Abordagem Instrumental."

\section{Conclusões}

Depois de analisar minuciosamente a história das publicações sobre tradução técnica e científica, parece evidente a existência de três períodos básicos no que concerne à pesquisa nessa área: até 1950 (que aparentemente não apresenta discussões sobre tradução técnica), 1951-1990 (média de 7,3\%) e de 1991 até os dias de hoje (mais que 10\%), apesar deste último ser demasiado curto e ainda precisar ser confirmado pelas décadas vindouras para que se ratifique a sua importância estatística para a área. 
Pode-se dizer que, até 1950, esse tipo de tradução não despertou nenhum tipo de interesse para os acadêmicos. Ao longo desses séculos, a tradução foi considerada uma atividade secundária, mais vista como uma atividade manual do que uma tarefa criativa ou eminente, e raramente digna de se estudar. O pouco interesse despertado nesse período se deveu unicamente a tradução de obras canônicas (obras clássicas e a Bíblia), deixando pouquíssimo espaço para a análise de textos instrumentais, nos quais a língua era vista como um elemento acessório e unívoco e, portanto, não oferecendo nenhuma problemática além do conhecimento técnico necessário que o tradutor deve possuir.

Entre os anos cinquenta e oitenta, os percentuais demonstram que não houve praticamente nenhuma mudança (uma diferença entre 6,3\% e $7,7 \%$ é muito pequena agora para ser considerada significante do ponto de vista estatístico), a ponto de ser possível considerar esses 40 anos da segunda metade do século vinte como um segundo estágio. Esse período, após a Segunda Guerra Mundial, pode ser considerado como o nascimento da abordagem científica da teoria da tradução. A principal diferença entre esse e todos os séculos anteriores é que os pesquisadores, sobretudo linguistas, agora tentam adquirir conhecimentos sistemáticos acerca dos problemas centrais da tradução em vez de meramente advogar métodos específicos de se traduzir. No caso da tradução técnica e científica, ocorreu um crescimento abrupto da repercussão na área, com números variando de $0 \%$ antes de 1950 para uma média de 7,3\% no período entre 1951 e 1980. Ainda é uma porcentagem muito baixa, se compararmos com a variação de $15 \%$ a $20 \%$ representada por verbetes sobre tradução literária e se considerarmos que a tradução técnica representa até $80 \%$ a $90 \%$ da demanda profissional para tradutores. A grande importância de publicações sobre literatura decorre provavelmente de seu alto status acadêmico, além da tradição filológica e literária de muitos autores contemporâneos que estudam tradução. Por outro lado, o declínio notável de discussões sobre tradução da Bíblia, que despenca dos $25 \%$ na primeira metade do século vinte para $4 \%$ nos anos noventa, evidencia que houve uma mudança substancial nos Estudos da Tradução, que parece se constituir numa disciplina buscando a própria autonomia ao deixar de lado o foco tradicional em obras canônicas para dar 
maior atenção a questões que, de fato, envolvem os tradutores. $\mathrm{O}$ status acadêmico de textos técnicos, de terminologia e de língua para fins específicos é uma questão muito moderna que apenas agora se torna comparável à literatura e à linguística "pura".

Ainda tratando de aspectos específicos, não se pode deixar de enfatizar o papel desempenhado pela Meta, publicada desde 1956 pela Universidade de Montreal, na área de tradução técnica e científica. Dentre os 543 verbetes técnicos coletados na BITRA entre 1966 e 1990, 231 (42,5\%) são artigos publicados no periódico, um fato certamente digno de estudo próprio. De qualquer forma, também importa ressaltar que a influência da $\mathrm{Me}$ ta nos Estudos da Tradução decaiu com o passar do tempo, o que significa que o interesse por tradução técnica não é um modismo criado pelo periódico, mas um propósito com cada vez mais autores, livros e outros periódicos também aderindo à causa. Desse modo, basta afirmar que os números referentes a artigos sobre tradução técnica publicados na Meta são 78/119 $(65,5 \%)$ nos anos setenta; 113/372 (30\%) nos anos oitenta; e 75/1,067 (7\%) nos anos noventa. Não houve modificações, naturalmente, na produção específica da Meta, ao passo que a produção global de pesquisas sobre tradução técnica e científica permaneceu crescendo todo o tempo.

Como pudemos observar, a Meta (um periódico multilíngue, mas que tem o francês como primeira língua) é também responsável pela situação peculiar observada na distribuição de línguas em suas publicações, contando com uma presença bem mais maciça do francês na tradução técnica do que em qualquer outra área. Tal qual o caso acima mencionado, o aumento desse tipo de trabalho em outros meios contribuiu para estabelecer um equilíbrio da distribuição de línguas na área de tradução técnica, tendo hoje o inglês como a sua primeira língua.

Assim voltamos aos dias de hoje, que parecem testemunhar um nítido aumento de publicações sobre tradução técnica e científica, saltando dos 7,3\% do período entre 1950 e 1980 para 10,2\% nos anos noventa, apesar de as características gerais das publicações não aparentarem ter sofrido muitas alterações. Quantos aos temas favoritos nas pesquisas sobre tradução técnica e científica, nota-se claramente a existência de quatro tipos de conhecimento hegemônicos no período entre 1950 e 2000: gêneros específi- 
cos, ensino, documentação e questões profissionais, todos demonstrando uma clara tendência em tratar de aspectos práticos em detrimento de abordagens altamente teóricas, algo que pode ser facilmente percebido, se levarmos em consideração que os quatro tipos de texto com palavras-chave específicas na BITRA (jurídico, empresarial, medicina e TI) representam 1.143 verbetes ( $60 \%$ do total de verbetes sobre tradução técnica) com muito mais em áreas técnicas variadas, da seguridade social a questões militares; enquanto o ensino de tradução técnica corresponde a 306 verbetes $(16 \%)$, documentação perfaz 200 verbetes (10,5\%), interpretação de discurso técnico totaliza 10,3\% com 197 verbetes e questões profissionais abrangem 147 verbetes $(7,7 \%)$.

Quanto aos gêneros específicos, tradução de textos jurídicos (ou da área de administração), sem dúvida, constitui-se no tema dominante na área técnica, exibindo um crescimento constante ao longo dos anos em que tem liderado, representando de forma surpreendente quase um terço (29\%) do total de pesquisas dedicadas à tradução técnica e científica. Portanto, os 552 verbetes dedicados a esse tipo de tradução se distribuem proporcionalmente desta forma: 10,5\% entre 1951 e 1960; 13,5\% entre 1961 e 1970; $26 \%$ entre 1971 e 1980; 25,8\% entre 1981 e 1990; e 31,6\% entre 1991 e 2000. Tradução de textos médicos, outro gênero textual de destaque na tradução técnica, atrai cerca de metade do interesse em assuntos jurídicos, com 299 verbetes globais $(15,7 \%)$. Tradução referente à área empresarial (155 verbetes) e de TI (137) ficam bem atrás, tendo o seu momento de ascensão apenas nas últimas décadas em virtude do gradual crescimento da importância do computador e do surgimento repentino da localização.

O ensino de tradução técnica e científica ( $16 \%$ dos verbetes sobre tradução técnica) é evidentemente o que mais desperta o interesse de pesquisadores dentro de uma disciplina, em que aspectos pedagógicos sempre foram considerados relevantes. Além disso, nota-se o constante crescimento de questões educacionais inseridas no campo técnico ${ }^{4}$ a partir de 1961, com

\footnotetext{
${ }^{4}$ A década de cinquenta representa o único período que aparenta romper com esta tendência com surpreendentes $13 \%$. Mas os itens sobre textos técnicos totalizam 38 para esta década, tanto que um ou dois verbetes podem fazer toda a diferença e não parece ser significante para a estatística. De fato, os números deste período, com 38 verbetes sobre tradução técnica, e da década de sessenta com 59 não são o suficiente para fornecer porcentagens parciais
} 
FRANCO AIXELÁ, O Estudo de Tradução Técnica e Científica

Traduzido por VIEIRA

8,5\% nos anos sessenta, 10,9\% nos anos setenta, 15\% nos anos oitenta e $17,3 \%$ nos anos noventa, o que se reflete no crescimento paralelo da tradução profissional nas universidades, resultando na maior presença de temas técnicos nos programas dos cursos.

A documentação se constitui naturalmente num tema-chave no que concerne à tradução técnica e científica, uma vez que aparece nos já mencionados 200 verbetes sobre documentação técnica $(10,5 \%$ destes sobre temas técnicos). Esse número perdura por toda a segunda metade do século vinte com uma única exceção não significativa nos anos sessenta, quando nenhum verbete sobre documentação técnica foi registrado. Esse tema parece marcar uma nítida diferença entre os interesses dos pesquisadores de tradução em geral e os que estudam especificamente tradução técnica e científica. Portanto, temos 10,7\% sobre documentação técnica nos anos noventa contra 3,4\% sobre documentação não técnica para o mesmo período. $\mathrm{O}$ mesmo ocorre nos anos oitenta, com 10,7\% sobre documentação técnica contra 3,5\% sobre documentação geral; e nos anos setenta a diferença é $10,1 \%$ contra $3,7 \%$. Evidentemente, a busca pelo termo correto é uma das características distintivas da tradução técnica e de sua teoria.

A análise de interpretação técnica também demonstra um nítido crescimento em nossa área como era de se esperar desse "parentesco" tradicional (mas que deixou de ser pobre) dos Estudos da Tradução. Logo, temos um crescimento dos verbetes sobre interpretação dos 3,4\% nos anos setenta para $10,7 \%$ nos anos oitenta e 11,6\% nos anos noventa. É surpreendente a comparação de tais números com a evolução da interpretação em geral durante a segunda metade do século vinte, tendo em vista que demonstra que a pesquisa sobre interpretação focava, a princípio (1951-1980), na interpretação em geral até o panorama se alterar por completo ao longo dos últimos vinte anos (1981-2000), com (proporcionalmente) muito mais verbetes sobre interpretação do discurso técnico do que sobre o não técnico. Os dados são os seguintes: entre 1951 e 1980, temos 1,8\% sobre interpretação técnica contra $4,5 \%$ sobre interpretação não técnica, enquanto entre

confiáveis em si, uma vez que determinadas obras podem alterar por completo a proporção correspondente à tradução técnica. 
1981 e 2000 as porcentagens foram de 11,1\% sobre discurso técnico diante de 7,2\% sobre não técnico. É claro que ambas as porcentagens crescem com o tempo tendo em vista que a interpretação tem se tornado mais importante nos Estudos da Tradução, mas pesquisas específicas parecem focar cada vez mais no tipo real de interpretação (técnica) que estagiários estão sujeitos a fazer, em detrimento de considerações mais teóricas e/ou gerais.

Por fim, questões profissionais correspondem a 7,7\% do total de verbetes sobre tradução técnica e científica em comparação aos 6,2\% sobre condições de trabalho em áreas técnicas não específicas. A diferença é insignificante do ponto de vista estatístico e tende a evidenciar um protagonismo quanto à eminência de aspectos profissionais nos Estudos da Tradução como um todo durante a segunda metade do século vinte, haja vista que se trata de uma disciplina com um ramo aplicado amplamente desenvolvido. Isso se torna ainda mais evidente para a tradução técnica, tendo em vista que corresponde a uma maioria esmagadora inserida na atividade tradutória, tanto que muitos verbetes não especificados como técnicos ("Uma Breve Descrição da Tradução na China", por exemplo) tratam em grande parte de tradução técnica e científica junto a outras áreas específicas como tradução literária ou audiovisual.

Gostaria de finalizar minha contribuição enfatizando que todos esses dados e porcentagens estão longe de ser conclusivos, uma vez que provêm daquilo que considero uma ferramenta bibliográfica bem representativa, porém ainda incompleta, a saber, a BITRA de setembro de 2003. Tanto que esses números e, em menor escala, as proporções modificar-se-ão na medida em que novos verbetes forem incluídos. De qualquer forma, creio que os resultados aqui discutidos se constituem numa indicação confiável das tendências demonstradas pelos itens referentes à tradução técnica e científica nos Estudos da Tradução.

Talvez a conclusão mais importante seja o fato de o desenvolvimento quantitativo ilustrado refletir a consolidação de nossa disciplina em virtude principalmente do surgimento de cursos universitários de tradução e o lançamento de diversos periódicos sobre tradução. Existe hoje um amplo público leitor diretamente envolvido na área de tradução, geralmente sobre tradução técnica em particular, e acadêmicos estão começando a desenvol- 
FRANCO AIXELÁ, O Estudo de Tradução Técnica e Científica

Traduzido por VIEIRA

ver uma nova percepção acerca de uma disciplina que finalmente se encontra protegida sob o manto da dignidade acadêmica. Ainda há muito a ser discutido e muitos querendo participar do debate, e há cada vez mais espaço para publicações para aqueles, agora livres da dependência de disciplinas coirmãs como Linguística e Estudos Literários, dispostos a contribuir para uma área antes considerada secundária. Não tenho ideia de quantos textos são publicados em todo o mundo sobre outras disciplinas, mas não tenho dúvida de que uma área de estudos que, nos anos noventa, abrangia, pelo menos (de acordo com registros da BITRA até setembro de 2003), mais de 1.000 publicações específicas por ano em todos os tipos de formatos acadêmicos e comerciais finalmente alcançou o seu amadurecimento pleno como disciplina acadêmica. Além disso, o lançamento de um novo periódico online, Journal of Specialised Translation, totalmente dedicado à tradução técnica e específica, sem dúvida, significa um aumento importante do número - e da qualidade também, espero - de publicações que lidem diretamente com esse tradicional 'primo pobre' dos Estudos da Tradução.

\section{Bibliografia}

ALPAC - Automatic Language Processing Advisory Committee - National Research Council (U.S.). Language and Machines: Computers in Translation and Linguistics Washington: National Academy of Sciences, 1966.

BENJAMIN, Walter. Die Aufgabe des Übersetzers [The task of the translator]. Preface to the German translation of 'Baudelaire: Tableaux Parisiens'. Heidelberg, 1923. It can be found in German in: BENJAMIN, Walter. 'Gesammelte Schriften'. Frankfurt: Suhrkamp, 82-96, 1972. English translation: "The task of the translator" in: CHESTERMAN, Andrew (ed.). Readings on Translation Theory, Helsinki: Oy Finn Lectura, 13-24, 1989. Also in: SCHULTE, Rainer \& BIGUENET, John (eds.). Theories of Translation: An Anthology of Essays from Dryden to Derrida. Chicago: University of Chicago Press, 71-82, 1992. Also in: VENUTI, Lawrence \& BAKER, Mona (eds.). The Translation Studies Reader. London: Routledge, 15-22, 2000. Tr. by Harry Zohn; with "A note on Harry Zohn's translation", by Steven Rendall, pages 23-25. Also in: TTR 10:2. The Translator's Task, Walter Benjamin (Traduction), Steven Rendall, 1997.

BITRA (http://www.ua.es/dfing/tra_int/bitra_en.htm). 
FRANCO AIXELÁ, O Estudo de Tradução Técnica e Científica

Traduzido por VIEIRA

COUTURE, Bruno. Quelques termes de soudage [Some terms related to welding]. Meta 17:3 (accessible on: http://www.erudit.org/revue/meta/), 1972.

CUNNINGHAM, Dale S. 1970. The Interaction of Literary and Technical Translators. In: Rabassa, Gregory (ed.). The World of Translation and its Teaching: A Seminar for Thinking Students. New York: Pen American Center, 39-52, 1971.

DELABASTITA, Dirk. Translation and the Mass Media. In: BASSNETT MCGUIRE, Susan \& LEFEVERE, André (eds.). TRANSLATION, HISTORY AND CULTURE. London: Pinter, 97-109, 1990.

DURIEUX, Christine. La créativité en traduction technique [Creativity in technical translation]. TextConText 6:1, 9-19, 1991.

FRANCO AIXELÁ, Javier. Prescriptivismo y descriptivismo: Objetivos de una teoría de la traducción [Prescriptivism and descriptivism: The aims of a theory of translation]. Jornadas Internacionales "Lenguas, Literatura y Traducción, Aproximaciones Teóricas" ( 1. 1998. Alicante). Madrid: Arrecife, 157-176, 2001.

GARCIA HIDALGO, I. \& DUNHAM, G.. An Experiment in EnglishSpanish Automated Translation of Medical Language Data. Methods of Information in Medicine 20:1, 38-46, 1981.

GARDNER, A. L.. Technical Translating Dictionaries. Journal of Documentation 6, 25-31, 1950.

GÉMAR, Jean-Claude \& HORGUELIN, Paul A. Bibliographie sélective du traducteur, Commerce et économie [A selected bibliography for the translator, Commerce and economy]. Montréal: Linguatech, 1977.

GRANDPRÉ, Jean-Paul de. Vocabulaire des assurances sociales [Vocabulary of social security]. Meta 12:1, 1967 (accessible on: http://www.erudit.org/revue/meta/).

HASKINS, Charles Homer. Arabic Science in Western Europe. Isis 5:2, 478485, 1925.

HENRY, Ronald. Terminologie des grades universitaires (3e partie et fin) [The terminology of university diplomas (3rd final part)]. Meta 16:3, 1971 (accessible on: http://www.erudit.org/revue/meta/).

HOLMSTROM, John Edwin. Report on Interlingual Scientific and Technical Dictionaries. Paris: Unesco, 1951.

HOLMSTROM, John Edwin (ed.). Scientific and Technical Translating and other Aspects of the Language Problem. Paris: Unesco, 1957.

HOOF, Henri Van. Réflexions sur le langue médical. Le point de vue du traducteur scientifique [Some reflections on medical language. The point of view of the scientific translator]. La Presse Médicale 67, 419-421, 1959. 
FRANCO AIXELÁ, O Estudo de Tradução Técnica e Científica

Traduzido por VIEIRA

------. Bibliographie de la traduction médicale [A bibliography of medical translation]. Meta 19:1, 43-66, 1974 (accessible on: http://www.erudit.org/revue/meta/).

HORGUELIN, Paul A. "La traduction technique" [Technical translation]. Meta 11:1 (accesible on http://www.erudit.org/revue/meta/), 15-31, 1966.

JUMPELT, Rudolf Walter (1959) (1963). "Methodological Approaches to Science Translation." CARY, Edmond \& JUMPELT, Rudolf Walter (eds.). Quality in translation - La qualité en matière de traduction. New York: Macmillan, 267-281, 1963.

------. Die Übersetzung naturwissenchaftlicher und technischer Literatur [Translating natural science and technical texts]. Berlin: Langenscheidt, 1961. The epilogue: "On the objectivazibility of translation", 184-187, is translated into English in: CHESTERMAN, Andrew (ed.). Readings on Translation Theory. Helsinki: Oy Finn Lectura, 1989, 33-36.

KALÉ, H. Technical Translating Services. Babel 2, 1956, 66-68.

LATHROP, H. B. Translations from the Classics into English from Caxton to Chapman, 1477-1620. Madison (Wisconsin): University of Wisconsin, 1933.

LINGUISTIC and Engineering Studies in the Automatic Translation of Scientific Russian into English: Technical Report. Seattle (Washington): Washington State University. Department of Far Eastern and Slavic Languages and Literature, 1958.

MEYERHOF, Max. On the Transmission of Greek and Indian Science to the Arabs. Islamic Culture 5, 17-29, 1937.

NIDA, Eugene Albert. Bible Translating: An Analysis of Principles and Procedures, with Special Reference to Aboriginal Languages. New York: American Bible Society, 1947.

ORTEGA Y GASSET, José. Miseria y esplendor de la traducción [The Misery and the Splendor of Translation]. In La Nación de Buenos Aires, 125162. English version in: SCHULTE, Rainer \& BIGUENET, John (eds.). Theories of Translation: An Anthology of Essays from Dryden to Derrida. Chicago: University of Chicago Press, 1992, 93-112. Also in: VENUTI, Lawrence \& BAKER, Mona (eds.). The Translation Studies Reader. London: Routledge. Title: The misery and the splendor of translation. Tr. Elizabeth Gamble Miller, 2000, 49-64. Also in: Translation Review 13:18-33. 1983. Tr. Carl R. Shirley.

ROBINSON, H. W. (ed.). The Bible in its Ancient and English Versions. Oxford: Clarendon Press, 1940.

SANZ, J. Le travail et les aptitudes des interprètes parlementaires [The task and the skills of parliamentary interpreters] Anals d'Orientació Professional 4, 303-318, 1931. 
FRANCO AIXELÁ, O Estudo de Tradução Técnica e Científica

Traduzido por VIEIRA

SCHLEIERMACHER, Friedrich Daniel Ernst. Über die verschiedenen Methoden des Übersetzens [On the different methods of translating]. Madrid: Gredos, 1813. English versions: LEFEVERE, André (ed.). Translation / History / Culture: A Sourcebook'. London: Routledge, 1992, p. 141-165. Also in Schulte, Rainer \& BIGUENET, John (eds.). Theories of Translation: An Anthology of Essays from Dryden to Derrida. Chicago: University of Chicago Press, 1992.

SIA, Gion Sing. Manual for Interpreters and Clerks of Courts. Kuala Lumpur: Federation of Malaysia: Government Printer, 1954.

STEYAERT, Chris \& JANSSENS, Maddy. Language and Translation in an International Business Context: Beyond an Instrumental Approach. Target 9:1, 131-154, 1997.

TYTLER, Alexander Fraser (1791, 1813). (1978). Essay on the Principles of Translation. Amsterdam: John Benjamins.

TRANSLATOR, Spanish and French. Preparatory Tests for Civil Service Examinations. Milwaukee (Wisconsin): Pergande, 1942.

VINAY, Jean Paul \& DARBELNET, Jean. Stylistique Comparée du Français et de l'Anglais. Méthode de traduction [Compared stylistics of French and English. A translation method] París: Didier, 1958.

YINGJUN, Xu. A Brief Description of Translation in China. Translatio 19:4, 412-416, 2000.

Resumo: O presente artigo tenciona demonstrar e explicar de forma minuciosa a evolução quantitativa e qualitativa da bibliografia de tradução técnica e científica ao longo da história em comparação a outros campos de pesquisa. O corpus levantado consiste nos mais de 20.000 verbetes obtidos na BITRA (Bibliografia de Interpretação e Tradução) até setembro de 2003. Essa ferramenta bibliográfica é um banco de dados multilíngue online cujo objetivo reside em abarcar tudo o que já foi publicado sobre tradução e que possa ser acessado livremente através do endereço http://www.ua.es/dfing/tra int/bitra_en.htm. A BITRA oferece um conjunto crescente (atualizado mensalmente) de verbetes bibliográficos, muitos com comentários, sobre tradução técnica. As principais palavras-chave estão incluídas na lista de palavras-chave, que pode ser acessada com apenas um clique. A pesquisa concluiu que o interesse por tradução técnica e científica se inicia apenas na década de 1950, motivado por uma suposta redução da obsessão em textos canônicos na área de Estudos da Tradução. Uma análise 
mais aprofundada também concluiu que este tipo de tradução ainda é visto como meramente funcional, o que se reflete em problemas decorrentes de domínios terminológicos (sobretudo da área jurídica e também da área médica, empresarial e tecnológica), ensino, documentação e interpretação do discurso técnico e questões profissionais como temas favoritos.

Abstract: This article tries to show and explain in some detail the quantitative and qualitative evolution of the bibliography on technical and scientific translation throughout history as compared with other research fields. The underlying corpus drawn on are the more than 20,000 entries collected in BITRA (Bibliography of Interpreting and Translation) up to September 2003. This bibliographical tool is an online multilingual database which attempts to comprise everything ever published on translation and can be freely accessed on http://www.ua.es/dfing/tra_int/bitra_en.htm The paper concludes that concern for technical and scientific translation only appears in the 1950s, when obsession with canonicity seems to decline somewhat within Translation Studies. A further finding is that consideration of this type of translation has been and remains mainly practical, with reflections on problems posed by terminological domains (mostly legal and, lagging far behind, medical, business and IT), teaching, documentation, the interpreting of technical discourse and professional issues as the favourite topics. 